\title{
A Comparative Study for Ease of Insertion of Laryngeal Mask Airway with Propofol and Thiopentone Sodium
}

\author{
Dr.Nirmala.B.C \\ Assistant professor, MVJ Medical College and research hospital Bangalore
}

\begin{abstract}
Background: The laryngeal mask airway (LMA) is a new form of airway which is introduced blindly into the hypo pharynx to form a seal around the larynx. Insertion of this LMA requires an adequate depth of anaesthesia, as the device is bulky and cannot be inserted unless jaw and pharynx are fully relaxed. The choice of the intravenous induction agent will influence the intubating conditions depending on its ability of obtunding the pharyngeal and laryngeal reflexes. This study was done to compare the conditions for insertion of LMA with thiopentone with fentanyl and propofol.

Materials and methods: This was a randomised prospective comparative study in which 100 adults scheduled for elective procedures under general anaesthesia were allocated to one of two groups. Patients were divided into two groups of 50 in each.

Results: The overall ease for insertion of LMA in thiopentone and fentanyl group was $92 \%$ and propofol group was $100 \%$ group $(p<0.05)$. Mouth opening and jaw relaxation were excellent in both the groups $(p=1)$. Swallowing was present in $10 \%$ of patients in thiopentone group $(p<0.05)$.

Conclusion: Intravenous propofol has been the preferred induction agent for LMA insertion till date. It provides smooth induction with depression of airway reflexes, allowing easier insertion of LMA with a reduced incidence of side effects such as coughing, gagging or laryngospasm. Thiopentone is easily available and commonly used compared to propofol (which is costly) in our rural setup. Induction of anaesthesia with propofol is associated with several side effects, including pain on injection, myoclonus, apnoea, hypotension, anaphylactic reaction and rarely, thrombophlebitis of the vein into which propofol is injected. Thiopentone sodium with fentanyl does increase the depth of anaesthesia to facilitate smooth insertion of LMA with minimum side effects.
\end{abstract}

Key words: laryngeal mask airway(LMA), thiopentone, propofol, fentanyl, ease of insertion.

\section{Introduction:}

The increasing emphasis on day care anaesthesia has led to the greater use of laryngeal mask airway (LMA) as an alternative to the face mask and in some cases to tracheal intubation. It ensures a better control of the airway leaving the anaesthesiologist's hands free. We conducted a comparative studyto assess the ease of laryngeal mask airway insertion after induction with propofol and thiopentone. Insertion of LMA requires adequate depth of anaesthesia and depression of the upper airway reflexes, as the device is bulky and cannot be inserted unless jaw and pharynx are completely relaxed.Intravenous propofol has been the preferred induction agent for LMA insertion till date. It provides smooth induction with depression of airway reflexes, allowing easier insertion of LMA with a reduced incidence of side effects such as coughing, gagging/swallowing or laryngospasm. Thiopentone is the cheapest drug, easily available and commonly used compared to propofol which is costly in our rural setup.

AIMS: To compare the conditions for insertion of LMA following induction of anaesthesia with

a) Thiopentone with fentanyl

b) Propofol

\section{Material And Methods:}

This study was carried out in the Department of Anaesthesiology in MVJ Medical College \&Research Hospital Dandupalya Bangalore rural from November 2009 to April 2012. Hundred patients coming for short surgical procedures of ASA class1 and 2 between 20-50 years of age were included in the study. The institutional ethical committee approved our study. Those adults having reactive airway disease or signs of upper respiratory infection, abnormal liver and kidney function tests were excluded from the study. We also excluded patients who had an abnormal airway, reflex oesophagitis and were obese ( $>50 \%$ of the ideal body weight).

All the patients were clinically evaluated, assessed and investigated prior to surgery. Written Informed consent was taken from all the patients. All the patients were fasted overnight and were given tab anxit $0.5 \mathrm{mg}$ and tab rantac $150 \mathrm{mg}$ orally previous night.

Patients were divided in to two groups fifty in each randomly. 
Group A - received thiopentone sodium $(5 \mathrm{mg} / \mathrm{kg})$ and fentanyl $(2 \mu \mathrm{g} / \mathrm{kg})$

Group B- received propofol $(2.5 \mathrm{mg} / \mathrm{kg})$.

Management of anaesthesia was similar in both the groups. Laryngeal mask airway was inserted after induction of anaesthesia. The presence of coughing, gagging/swallowing, laryngospasm, limb movements were noted and graded along with mouth opening and jaw relaxation.

On arrival of patients to the operating room, an intravenous line was established and monitoring instituted for continuous monitoring of ECG, heart rate, non-invasive blood pressure, end tidal carbondioxide and oxygen saturation. Baseline readings of heart rate, blood pressure (systolic and diastolic) were recorded before induction of anaesthesia.Injglycopyrolate $0.003 \mathrm{mg} / \mathrm{kg}$ was administered IV $10 \mathrm{~min}$ before the anaesthetic induction. Patients were preoxygenated for $3 \mathrm{~min}$ with $100 \%$ oxygen. General anaesthesia was induced in group A thiopentone sodium $5 \mathrm{mg} / \mathrm{kg}$ and fentanyl $2 \mu \mathrm{g} / \mathrm{kg}$ in group B $2.5 \mathrm{mg}$ of Inj propofol. All patients had the LMA inserted as soon as the eyelash reflex was suppressed. LMA size was chosen as per body weight. All the patients were evaluated for incidence of coughing, gagging /swallowing, laryngospasm, limb movements, ease of insertion and jaw relaxation. The data collected was compiled and analyzed statistically using students' $t$ ' test. A 'p' valve of $<0.05$ was considered significant. We have not used any muscle relaxants for insertion of LMA. After LMA insertion, anaesthesia was maintained with $33 \%$ oxygen and $66 \%$ nitrous oxide along with halothane.

\section{AGE DISTRIBUTION OF PATIENTS}

\begin{tabular}{|l|l|l|l|l|}
\hline Age in years & $\begin{array}{l}\text { Group A } \\
\text { No of pts }\end{array}$ & Percentage & $\begin{array}{l}\text { Group B } \\
\text { No of pts }\end{array}$ & Percentage \\
\hline $20-30$ & 13 & $26 \%$ & 12 & $24 \%$ \\
\hline $31-40$ & 21 & $42 \%$ & 23 & $46 \%$ \\
\hline $41-50$ & 16 & $32 \%$ & 15 & $30 \%$ \\
\hline Total & 50 & $100 \%$ & 50 & $100 \%$ \\
\hline
\end{tabular}

The participants took part in this project were in the age group of $20-50$ years. $42 \%$ of patients in group I and $46 \%$ of patients in group II are belonged to age group between 31- 40 years and mean age in group I was 38.24 \pm 10.55 and mean age in group II was $39.94 \pm 11.80$ and were comparable among two groups. $(p>0.05)$

\section{SEX DISTRIBUTION}

\begin{tabular}{|l|l|l|l|l|}
\hline Sex & $\begin{array}{l}\text { Group A } \\
\text { No of pts }\end{array}$ & Percentage & $\begin{array}{l}\text { Group B } \\
\text { No of pts }\end{array}$ & Percentage \\
\hline Male & 24 & $48 \%$ & 18 & $36 \%$ \\
\hline Female & 26 & $52 \%$ & 32 & $64 \%$ \\
\hline Total & 50 & $100 \%$ & 50 & $100 \%$ \\
\hline
\end{tabular}

100 patients of each sex had participated on this study group. Both have predominantly female patients $52 \%$ in group I and $64 \%$ in group II.

The demography data with respect to age, sex, ASA status was statistically not significant.

Adverse responses to airway manipulation such as coughing, gagging/ swallowing, laryngospasm and limb movements were graded as absent, mild, moderate and severe.

\section{ADVERSE RESPONSE TO AIRWAY MANIPULATION GRADING:}

\begin{tabular}{|l|l|l|}
\hline 1. & Absent & ---- \\
\hline 2. & Mild & Transient and minimal lasting < 5 seconds \\
\hline 3. & Moderate & Lasted $>5$ seconds, but resolved spontaneously within 20 seconds \\
\hline 4. & Severe & Sustained $>20$ seconds or required additional boluses of drugs \\
\hline
\end{tabular}

\section{COUGHING}

\begin{tabular}{|l|l|l|}
\hline & $\begin{array}{l}\text { Thiopentone sodium with } \\
\text { fentanyl }\end{array}$ & Propofol \\
\hline Absent & 46 & 48 \\
\hline Mild & 4 & 2 \\
\hline Moderate & - & - \\
\hline Severe & - & - \\
\hline
\end{tabular}


Mild coughing was observed in 4 patient in thiopentone group, and 2 patients in propofol group $(\mathrm{p}=0.31)$.

\section{GAGGING/SWALLOWING}

\begin{tabular}{|l|l|l|}
\hline & $\begin{array}{l}\text { Thiopentone sodium with } \\
\text { fentanyl }\end{array}$ & Propofol \\
\hline Absent & 30 & 36 \\
\hline Mild & 15 & 14 \\
\hline Moderate & 5 & - \\
\hline Severe & - & - \\
\hline
\end{tabular}

Mild degree of swallowing/gagging was present in 14 of patientsinpropofol group compared to 15 patients inthiopentone group statistically not significant. Moderate degree of swallowing/gagging was present in 5 patients in thiopentone group and absent in popofolgroup ( $\mathrm{p}<0.01$ significant).

\section{LARYNGOSPASM}

\begin{tabular}{|l|l|l|}
\hline & $\begin{array}{l}\text { Thiopentone sodium with } \\
\text { fentanyl }\end{array}$ & Propofol \\
\hline Absent & 50 & 50 \\
\hline Mild & - & - \\
\hline Moderate & - & - \\
\hline Severe & - & - \\
\hline
\end{tabular}

Laryngospasm was absent in both the groups $\quad(p=0)$

\section{LIMB MOVEMENTS}

\begin{tabular}{|l|l|l|}
\hline & $\begin{array}{l}\text { Thiopentone sodium with } \\
\text { fentanyl }\end{array}$ & Propofol \\
\hline Absent & 42 & 49 \\
\hline Mild & 8 & 1 \\
\hline Moderate & - & - \\
\hline Severe & - & - \\
\hline
\end{tabular}

There were mild patient movements in 1 patient in propofol group whereas 8 patients had mild movements in thiopentone group ( $\mathrm{p}<0.01$ significant).

\section{JAW RELAXATION:}

\begin{tabular}{|l|l|l|}
\hline & Thiopentone sodium with fentanyl & Propofol \\
\hline Excellent & 50 & 50 \\
\hline Satisfactory & - & - \\
\hline Poor & - & - \\
\hline
\end{tabular}

Jaw relaxation were excellent in both the groups $(\mathrm{p}=1)$.

The ease of insertion of LMA and jaw relaxation was graded as excellent, satisfactory and poor

\begin{tabular}{|r|l|l|}
\hline 1 & Excellent & No/mild adverse responses subsided within 5seconds. \\
\hline 2 & Satisfactory & Mild adverse response to airway manipulations, but not affecting the insertion of LMA \\
\hline 3 & Poor & Moderate-to-severe adverse responses or More than two attempts required for insertion \\
\hline
\end{tabular}

THE EASE OF INSERTION:

\begin{tabular}{|l|l|l|}
\hline & $\begin{array}{l}\text { Thiopentone sodium with } \\
\text { fentanyl }\end{array}$ & Propofol \\
\hline Excellent & 39 & 42 \\
\hline Satisfactory & 7 & 8 \\
\hline Poor & 4 & - \\
\hline
\end{tabular}

There was easy insertion of LMA in 42 patients in propofol group compared to 39 in thiopentone group. It was considered difficult in 4 patients in thiopentone group. However, insertion was possible in all patients. The 
statistical analysis by Chi square test showed that ease of insertion was significantly better in patients who were administered propofol compared to those given thiopentone and fentanyl. (p value <0.01 - significant). The overall ease for insertion of LMA in thiopentone and fentanyl group was 92\% and propofol group was $100 \%$ $(\mathrm{p}<0.001$ significant).

\section{Discussion:}

The laryngeal mask airway introduced in 1983 by Dr.Archie Brain has revolutionized the airway management in many patients who would have otherwise undergone endotracheal intubation or received anaesthesia through the conventional facemask. This device with its ease of use helps the anaesthesiologist by keeping his hands free for other work. It also avoids the adverse effects of endotracheal intubation.

Laryngeal mask insertion is based on a close imitation of the swallowing mechanism ${ }^{1}$ The standard insertion technique combines the ability to insert it blindly, avoiding collision with the highly innervated anterior pharyngeal structures such as the vallecula, epiglottis, glottis and arytenoids. The insertion technique does not require use of laryngoscopy or muscle relaxants and is designed to simulate the mechanism of a food bolus being swallowed. During swallowing, the tongue acts as semicircular rim sweeping and flattening the food bolus around the curved wall formed by the palate and posterior part of pharynx. LMA insertion is achieved by a similar action with the index finger substituting the action of the tongue. Insertion of the mask is relatively non-stimulating, as instrumentation and manipulation of structures associated with noxious reflex responses are avoided. To obtain optimal placement in the hypo pharynx, the appropriate sized mask should be inserted, with the reflexes obtunded either by general or topical anesthesia. This standard technique was described by the Dr.Archie Brain. This technique appears to offer superior results in terms of function and the final anatomical position in adult. A lubricant ( $2 \%$ lignocaine Jelly), is applied just to the posterior surface of the cuff. Even though patients can tolerate the LMA under light anaesthesia, it is better to maintain anaesthesia deep enough to suppress airway reflexes. Both spontaneous breathing and controlled ventilation can be achieved through the LMA.

Intravenous propofol has been the preferred induction agent for LMA insertion. It provides smooth induction with depression of airway reflexes, allowing easier insertion of LMA with a reduced incidence of side effects such as coughing, gagging or laryngospasm. Induction of anaesthesia with propofol is associated with several side effects, including pain on injection [greater than that after thiopentone], myoclonus, apnoea, hypotension, anaphylactic reaction and rarely, thrombophlebitis of the vein. The cardiovascular depressant properties of propofol are similar or greater than those of thiopentone. Propofol is likely to cause profound hypotension in hypovolemic or previously hypertensive patients and those with cardiac disease. Propofol causes more prolonged respiratory depression compared to thiopentone. But propofol is an ideal drug for day case anaesthesia because of its rapid recovery, no cumulative effects and lower incidence of nausea and vomiting. It is an ideal agent for total intravenous anaesthesia as there is quick recovery on cessation of the infusion. Propofol with a short acting opioid is a safe and effective standard balanced technique for maintenance of anaesthesia.

Thiopentone is (cost effective) the cheapest drug, easily available and commonly used compared to propofol which is relatively expensive costly and not easily available in our rural setup. Thiopentone is a potent cerebral depressant. Hypertensive and hypovolemic patients are more sensitive to thiopentone, characterised by exaggerated hypotensive effects. The degree of respiratory depression depends on dose, rate of injection and type of premedication. Even today thiopentone remains the gold standard for intravenous induction agents against which all newer compounds are compared.

In 1991, Brown GW, et al, ${ }^{2}$ compared propofol and thiopentone for laryngeal mask insertion. The study included 80 patients of ASA Grade-I or II aged between 18 and 70 years. All were premedicated with diazepam 10mg orally 2 hours before the operation and were induced with the fentanyl $1 \mathrm{mcg} / \mathrm{kg}$, followed by equipotent doses of either propofol $2.5 \mathrm{mg} / \mathrm{kg}$ or thiopentone $4 \mathrm{mg} / \mathrm{kg}$ given over $30 \mathrm{secs}$. Results showed significantly higher incidence of coughing and gaging in thiopentone group. Out of 40 patients in each group 2 patients in propofol group and 12 patients in thiopentone group had gagging.He suggested that propofol is either more effective at providing satisfactory conditions or that the thiopentonedoses used were not equipotent for insertion of laryngeal mask.

In 1993, a study was undertaken by Pramod Bapat ${ }^{3,}$ et al, wherein a comparison was made between propofol versus thiopentone with midazolam or lidocaine to facilitate laryngeal mask insertion. 150 patients equally divided into 3 groups scheduled for elective surgeries were recruited. Anaesthesia induction was done with $1 \mathrm{mcg} / \mathrm{kg}$ fentanyl followed by either $2.5 \mathrm{mg} / \mathrm{kg}$ propofol (group P) or a sequence of $1.5 \mathrm{mg} / \mathrm{kg}$ lidocaine and $5 \mathrm{mg} / \mathrm{kg}$ thiopentone (group LT), or midazolam $0.1 \mathrm{mg} / \mathrm{kg}$ and $3 \mathrm{mins}$ later thiopentone $5 \mathrm{mg} / \mathrm{kg}$ (group MT). The LMA was inserted by a blinded anaesthetist who assessed and graded the conditions for LMA insertion and noted any adverse response. Excellent conditions were observed in 96\% in MT group, 92\% in P group and $68 \%$ 
in LT group. They concluded that with the above doses, a fentanyl-midazolam-thiopentone combination which is about $35 \%$ less expensive than fentanyl-propofol provides equally good conditions for insertion of LMA. In 2004, VandanaTalwar, et $\mathrm{al}^{4}$, compared propofol versus thiopentone for facilitation of laryngeal mask insertion. 50 ASA grade 1 patients were administered equipotent doses of propofol (group P), or thiopentonegroup T), after pre induction doses of midazolam $(0.04 \mathrm{mg} / \mathrm{kg})$ and fentanyl $(1.5 \mathrm{mcg} / \mathrm{kg})$. Conditions for insertion were graded on a three-point scale, using six variables. They found that ease of insertion was significantly greater with propofol as compared to thiopentone. They considered easy in $96 \%$ patients in propofol group and $76 \%$ in thiopentone group. Jaw relaxation was full in $88 \%$ in propofol group as against $80 \%$ in thiopentone group.Haemodynamic parameters measured during induction revealed, a significantly greater decrease in heart rate and arterial pressures in propofol group as compared to the thiopentone group.

Keerthikumar S, in $1998^{5}$, compared the effectiveness of thiopentone use with that of propofol for insertion of laryngeal mask airway. One group received thiopentone $5 \mathrm{mg} / \mathrm{kg}$ with $10 \%$ lignocaine spray topically to the larynx and the other group received propofol $2.5 \mathrm{mg} / \mathrm{kg}$. The occurrence of gagging, coughing, and laryngospasm were noted. It was observed that thiopentone with local anaesthetic spray to larynx for insertion of LMA produced the same ease as that of propofol use.

Seavell CR, et al, in 1995, studied the effects of topical lignocaine and thiopentone for the insertion of laryngeal mask airway and compared it with propofol. Conditions for insertion of laryngeal mask airway were assessed in 90 unpremedicated adult patients who received either thiopentone $5 \mathrm{mg} / \mathrm{kg}$ preceded by $40 \mathrm{mg}$ of topical lignocaine spray to the posterior pharyngeal wall or propofol $2.5 \mathrm{mg} / \mathrm{kg}$ alone. All patients received fentanyl $1 \mathrm{mcg} / \mathrm{kg}$. Gagging, coughing, and laryngospasm following laryngeal mask insertion were graded and haemodynamic data and apnoea times were recorded. There was no significant difference between the two groups with regard to incidence of gagging, coughing, and laryngospasm, but apnoea time was significantly lesser in thiopentone group. The decrease in systolic and diastolic blood pressure following induction with propofol was significantly greater than following thiopentone, It was concluded that thiopentone preceded by topical lignocaine spray provides conditions for laryngeal mask insertion equal to those of propofol, with more haemodynamic stability and shorter period of apnoea.

Patrick Scanlon, et $\mathrm{al}^{7}$, in 1993 , assessed the patient responses to laryngeal mask insertion after induction of anaesthesia with propofol $2.5 \mathrm{mg} / \mathrm{kg}$ or thiopentone $5 \mathrm{mg} / \mathrm{kg}$. The presence of gagging, coughing, laryngospasm and patient movement was noted and graded. Thiopentone was associated with an adverse response in $76 \%$ of patients compared with $26 \%$ in propofol. No patient in propofol group required treatment for laryngospasm. No patient was judged to be inadequately relaxed in propofol group and this was less than $11 \%$ in the thiopentone group. It was concluded that at these doses, propofol was superior to thiopentone as an induction agent for insertion of laryngeal mask airway.

In our study there was no difference in the incidence of laryngospasm jaw opening, coughing and mild degree of gagging between the two groups. The undesired responses was found to be slightly more in thiopentone group compared to propofol group, they were statistically significant. However, Thiopentone sodium with fentanyl does increase the depth of anaesthesia to facilitate smooth insertion of LMA with minimum side effects.Both propofol and thiopentone with fentanyl serve the purpose of insertion of LMA.

\section{Conclusion:}

In conclusion, ease of insertion of LMA was significantly greater in patientswho were induced with propofol compared to induction with thiopentone sodium and fentanyl. However, there was no difference in the incidence of jaw relaxation, coughing, laryngospasm and limb movements between the two groups. Swallowing/gagging was present in $10 \%$ of patients in thiopentone group.

Bibliography:

[1]. Brimacombe J, Berry A. Active swallowing to aid laryngeal mask airway insertion in awake patients. Anaesthesia Analgesia.1994; 78: 1029-1030.

[2]. Brown GW, Patel N, Ellis FR. Comparison of propofolandthiopentone for laryngeal mask insertion. Anaesthesia 1991; 46: 771772.

[3]. PramodBapat, Joshi N, Edward Young. Comparison of propofol versus thiopentone with midazolam or lidocaine to facilitate laryngeal mask insertion. Can J Anaesth 1993; 43: 564-568.

[4]. VandanaTalwar, Rajesh Pattanayak, SujeshBansal. Comparison of propofol versus thiopentone for facilitation of laryngeal mask insertion. J AnaesthClinPharmacol 2004; 20(1): 33-38.

[5]. Keerthi Kumar S. A comparative study of agents for insertion of laryngeal mask airway. Ind J Anaesth 1998; 42: 27-29.

[6]. Seavell CR, Cook TM, Cox CM. Topical lignocaine and thiopentone for the insertion of a laryngeal mask airway. Anaesthesia 1996; 51: 699-701.

[7]. Patrick Scanlon, Michael Carey, Michael Power. Patient response to laryngeal mask insertion after induction of anaesthesia with propofol or thiopentone. Can J Anaesth 1993; 40: 816-818.

[8]. Driver IK, Wiltshire S, Mill P, Lillywhite N, Howard-Griffin. Midazolam coinduction and laryngeal mask insertion. Anaesthesia 1996; 51: 782-784.

[9]. Driver I, Wilson C, Wiltshire S, Mills P, Howard-Griffin. Co-induction and laryngeal mask insertion. A comparison of thiopentone versus propofol.Anaesthesia 1997; 52: 695-703. 
[10]. Gill PS, Shah J, Ogilvy A. Midazolam reduces the dose of propofolrequiredfor induction of anesthesia and laryngeal mask airway insertion. Eur J Anaesth2001; 18(3): 166-170.

[11]. Goyagi T, Tanaka M, Nishikawa T. Fentanyl decreases propofolrequirementfor laryngeal mask airway insertion. ActaanaesthesiologicaScandinavica.2003; 47(6): 771-774 